\title{
Model of copepod growth and development: moulting and mortality in relation to physiological processes during an individual moult cycle
}

\author{
François Carlotti, Paul Nival
}

Station Zoologique, U.A. 716, BP 28, F-06230 Villefranche-sur-Mer, France

\begin{abstract}
A mathematical model of copepod population dynamics coupling individual growth and development was tested. The results show in detail the effect of applying various hypotheses, particularly concerning the relationship between certain physiological processes (ingestion, egestion, excretion, oogenesis, etc.) and processes controlling the time course of abundance of individuals in each instar (mortality rate, moulting rate, reproduction). The model shows the changes in physiological processes (ingestion, growth rate, etc.) at the individual level as a function of age within stage, and consequently the probability of moulting and death. If an individual remains for some time at one stage, its growth rate decreases, weight does not increase, the ability to moult is lost and the probability of death is greater. In addition, the model gives the mean values of processes for the whole population, as could be obtained experimentally, but it also provides an explanation of the variability of processes related to the population age structure. Finally, the results of this mathematical model led to an experimental test of the validity of the hypotheses put forward. The mathematical model can be used in all conditions, since it simulates values of processes constant in time as long as the external conditions are also constant, while remaining capable of expressing the internal dynamics of a population when the environment is suddenly perturbed.
\end{abstract}

\section{INTRODUCTION}

For a better understanding of the dynamics of a planktonic population within the pelagic ecosystem, 2 types of processes should be considered: demographic (flux of animals) and biogeochemical (cycles of matter). Yet these 2 approaches are quite often modelled separately (Cale 1988) for 2 reasons. The researcher may be more interested in the behaviour of the ecosystem (flux of matter) or, on the other hand, he may focus his study on a single population or even on a particular developmental stage (e.g. recruitment). In models of larval dynamics, development and mortality rates generally are linked directly to external parameters (food, temperature) by empirical relationships, which do not take into account the energetic processes involved in dynamics (Davis 1984, Sciandra 1986). In fact, these external parameters affect the physiology of organisms in several ways, either ensuring normal development or inducing developmental difficulties, even death. Moreover, these physiological steps act as filters for certain variations of external parameters, which are subject to strong fluctuations in the pelagic environment, and contribute to time lags observed in population dynamics.

In order to describe population dynamics in terms of individuals and biomass simultaneously, a model must take into account the energy characteristics of the individual and how they are connected with demographic processes (Steele \& Mullin 1977). Successful studies are often made of the relationships between external variables and the physiological functions which control the energy budget (ingestion, excretion, egestion, reproduction), whereas relationships between energetic (growth) and demographic processes (moulting, mortality) are difficult to assess experimentally.

A conceptual scheme has been proposed in the model established by Carlotti \& Sciandra (1989) and Carlotti (1990), which integrates biomass and demographic criteria simultaneously. In this model, the processes involved in individual growth (ingestion, 


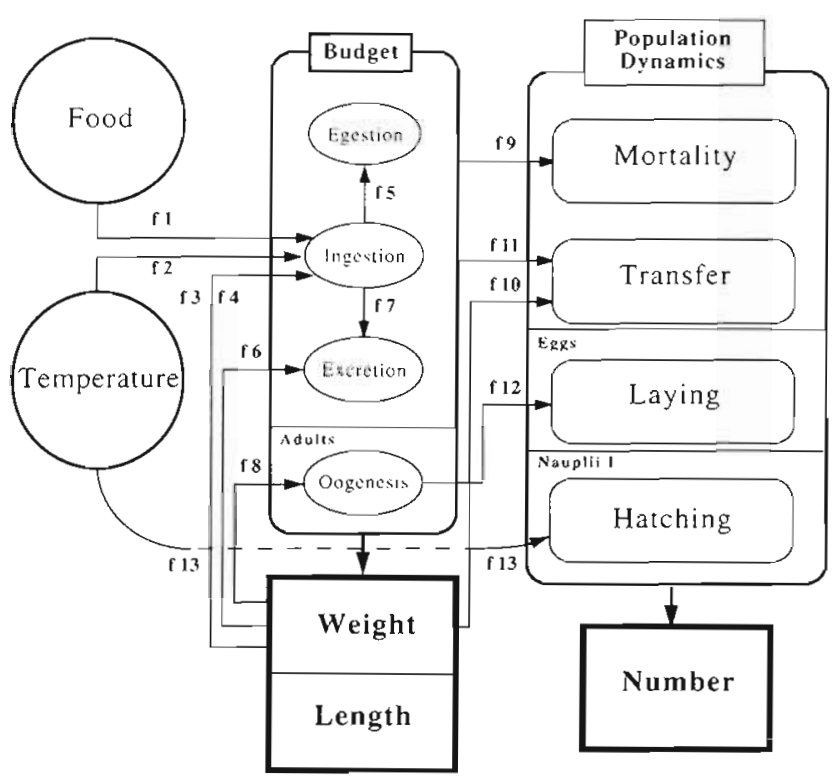

Fig. 1. Conceptual diagram of the model. Relationships (f) between external forcing variables, physiological processes and population dynamics terms are detailed in Fig. 3

egestion, excretion, oogenesis) are coupled with processes controlling the time course of the abundance of individuals at each stage (mortality, moulting and reproduction rates) (Fig. 1).

Using this model we were able to simulate the growth and development of Euterpina acutifrons simultaneously (quantitative validation) and to define general rules concerning the growth and development of small copepods (qualitative validation). Moreover, this model fits the time series of stages of a Euterpina acutifrons population raised in the laboratory (Fig. 3 in Carlotti \& Sciandra 1989) better than a model using empirical formulations (Sciandra 1986; see his Fig. 5). A deterministic explanation of the asymmetry of the time course curves of abundance for each stage has been suggested. In Carlotti \& Sciandra (1989), the results presented mainly concerned the time courses of the state variables: number in each stage, weight of individuals and biomass of the population.

Here, we give a description of the fundamental internal characteristics of this model and explain how it can provide the basis for an experimental study of a copepod population (Carlotti \& Nival 1992). Moreover, the model permits observational access to processes and variables which cannot be assessed directly in experimentation. We indicate the time courses of the processes of mortality and transfer to the next stage (moulting) during development at each stage, and test the functional connections with the physiological processes at the individual level. The hypotheses concerning these functional connections are:
Hypothesis 1. In the absence of predators and parasites, the probability of death depends directly on the physiological state of the individual, which is a consequence of the past feeding history of the animal. This hypothesis has already been formulated for fish (Wroblewski 1984).

Hypothesis 2. Moulting occurs (1) when a given weight is reached (critical moulting weight) and (2) if the physiological state during a short period preceding the moult is favourable.

Hypothesis 3. Individual weight cannot exceed a maximum value in a stage, because the exoskeleton limits growth. Thus, if the animal goes above the critical moulting weight, ingestion decreases as a function of the excess biomass of this critical weight.

The purpose of this report is to present in detail the consequences of these biological hypotheses regarding the pattern of mortality and moulting rates during the moulting cycle. The simulations described here supplement those which have already been presented concerning the population dynamics of Euterpina acutifrons (Carlotti \& Sciandra 1989).

\section{THE MODEL}

The conceptual basis of the model has already been described in detail (Carlotti \& Sciandra 1989). In this paper, we focus on the influence of variables affecting the physiological processes involved and on the interaction of processes.

\section{Scope of the model}

The development of copepods can be divided into 2 levels (Fig. 2). The first one corresponds to the developmental instars: eggs ( $i=1)$, nauplii $(i=2$ to 7 ), copepodites ( $\mathrm{i}=8$ to 12 ) and adults; while the second level concerns the age classes within each stage. The choice of the duration of an age class is up to the person using the model. The number of age classes within a stage must be large enough to allow maximum duration at each stage.

In each age class, the variations in mean individual weight and in the numbers of individuals are calculated as a function of various biological processes, which are linked as shown in Fig. 1. The differential equations of the model are given in Table 1 , and the mathematical formulations of the processes are given with Fig. 3 (see also Table 1 in Carlotti \& Sciandra 1989).

Here results are presented for the first 2 feeding stages (NI and NII) of Euterpina acutifrons, as it is easier to illustrate some processes of population dynamics at the early stages (see Fig. 8 in Carlotti \& Sciandra 1989). 


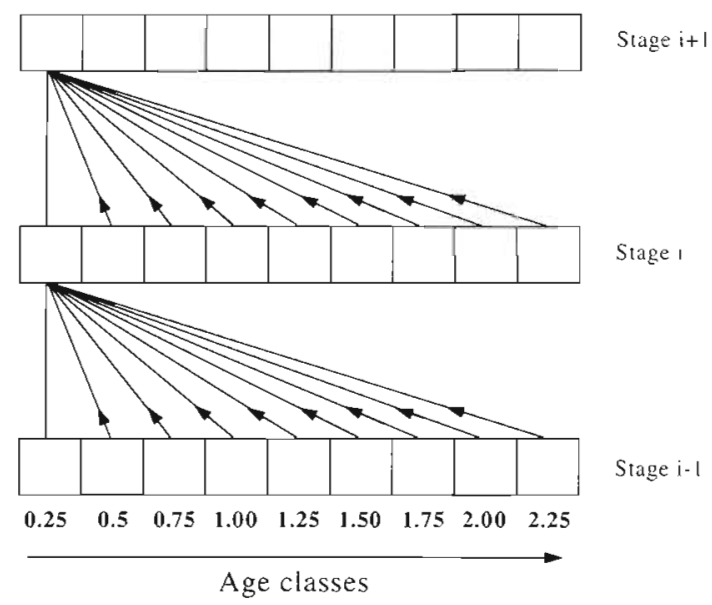

Fig. 2. Conceptual framework of the model. Copepod development can be divided into stages (natural partition), and each stage can be divided into age classes all having the same duration (artificial partition). Duration of age classes was chosen as $0.25 \mathrm{~d}$ in the simulations. Arrows denote that a proportion of larvae can reach the first age class of the next stage. This transfer depends on physiological factors, which only become adequate for some age classes (see 'Simulations')

Indeed, these stages closely reflect egg production pulses, whereas at later stages this correspondence becomes damped by variability due to the asynchronal development of individuals, which increases progressively (Carlotti \& Nival 1991). Nevertheless, we could have chosen another stage for presenting these results, because the mechanical representation (the mathematical functions as a whole) of the growth and development in the different stages is the same.

\section{Physiological processes}

The choice of the mathematical formulations of physiological processes is justified in Carlotti \& Sciandra (1989) with regard to the literature. Fig. 3 shows the plots of the functions presented in Fig. 1.

At any given time, 3 variables influence ingestion (Fig. 3A to D): food concentration (F), temperature (Te) and mean individual weight $(W)$ in an age class. This representation is a simplification of the factors known to influence ingestion (Huntley 1988). The relationship between ingestion and food concentration (Fig. 3A) has been studied experimentally for Euterpina acutifrons by Sciandra (1982), who determined the sigmoidal function $\mathrm{f} 1$.

Temperature affects enzymatic reactions and hence bioenergetic processes. Experiments on copepods have shown its impact on ingestion (Mullin \& Brooks 1970, Kiørboe et al. 1982, Thébault 1985), assimilation (Conover 1966), excretion (Ikeda 1985) and respiration
(Huntley \& Boyd 1984, Ikeda 1985). However, the effect of temperature is rarely estimated by the activity of the enzymes involved in a given process, but by the variation in the flux of matter generated by the activity of enzymes. In fact, the influence of temperature on only one of these processes can be limiting for the general functioning of the matter budget. Concerning copepods, there are 2 opposing points of view in this respect: the first is that copepod growth can be described by temperature alone (Paffenhöfer \& Harris 1976, McLaren 1978), whereas the second considers food as a limiting factor (Mullin \& Brooks 1976. Checkley 1980, Huntley \& Boyd 1984). In fact, the response to these parameters is more complex, as the effect of temperature may differ with food concentration (Thébault 1985)

For a parameter with such a complex influence as temperature, the modeller has to answer 3 questions: (1) Which processes are likely to be modified by temperature? (2) Which coefficients of the mathematical functions of processes change with temperature? (3) Which mathematical representation should be used for the effect of temperature on the coefficients chosen?

To simplify matters, we considered the action of temperature on the ingestion rate only (Fig. 3B), since catabolic processes are related to ingestion and therefore indirectly to temperature. This implies that ingestion rate limits the whole budget. The influence of temperature on the maximum ingestion rate can be expressed as an exponential within the range 10 to $25^{\circ} \mathrm{C}$, which is not extreme for Euterpina acutifrons (see Carlotti \& Sciandra 1989).

The influence of weight on physiological processes has been widely demonstrated. In the present model, weight is linked with ingestion, excretion and reproduction.

Two weight functions (f3 and f4) which account for different phenomena influence the ingestion rate (Fig. 3C, D). The allometric law (function $\mathrm{f} 3$ ) is determined experimentally by analyzing the total growth of the copepod. This signifies that the ingestion rate per unit weight decreases as weight increases (Paffenhöfer $1971,1984)$. This empirical relation is due to complex genetical and physiological phenomena occurring as the individual grows older, and is quite often used in models (Steele 1974, Kremer \& Nixon 1978). The second function (f4) concerns the copepod's mode of life during the moulting cycle. It was not included in previous versions of the model (Carlotti 1986, 1987, Nival et al. 1988). The results obtained with these versions have revealed a certain abnormality: some individuals in a given stage, i.e. those which developed slowly, continued to grow within that stage. Obviously, however, copepods are prevented by their exoskeleton from growing indefinitely in one stage, as moulting is the only way in which the organism can keep growing. For individuals 
Table 1. Processes and system of differential equations describing dynamics of copepod individuals and populations. i: stage; $\mathrm{j}$ : age class; $W_{1,1}$ : weight; $\mathrm{N}_{4,4}$ : abundance

\begin{tabular}{|c|c|c|c|}
\hline Process & Units & Formulation & \\
\hline \multicolumn{4}{|l|}{ Growth } \\
\hline Ingestion (I) & $\mu g$-at. $\mathrm{N} \mathrm{d}^{-1} \mathrm{i}^{-1}$ & $I_{i, j}=f 1_{i, j} \cdot f 2_{i, j} \cdot f 3_{i, j} \quad f 4_{1, j}$ & (1) \\
\hline Egestion (EG) & $\mu g-a t . N^{-1} i^{-1}$ & $E G_{i, j}=f 5_{i, j}$ & (2) \\
\hline Excretion $(E X)$ & $\mu \mathrm{g}$-at. $\mathrm{Nd}^{-1} \mathrm{i}^{-1}$ & $E X_{i, j}=f 6_{i, j}+f 7_{i, j}$ & (3) \\
\hline Matter for reproduction (MR) & $\mu \mathrm{g}$-at. $\mathrm{Nd} \mathrm{d}^{-1} \mathrm{i}^{-1}$ & $M R_{13 . j}=f 8_{13 . j}$ & (4) \\
\hline Growth $(\mathrm{G})$ & $\mu \mathrm{g}$-at. $\mathrm{Nd}{ }^{1} \mathrm{i}^{-1}$ & $G_{i, j}=I_{i, j}-E X_{i, j}-E G_{i, j}$ & (5) \\
\hline Specific growth (SG) & $d^{-1}$ & $S G_{i, j}=\frac{G_{i, j}}{W_{i, j}}$ & (6) \\
\hline Cumulated specific growth (CSG) & $d^{-1}$ & $\operatorname{CSG}_{i, j}=\frac{1}{\Delta t} \cdot \int_{t-\Delta t} S_{i, j} \cdot d t$ & (7) \\
\hline \multicolumn{4}{|l|}{ Dynamics } \\
\hline Mortality (M) & $d^{-1}$ & $M_{1, j}=f g_{i, j}$ & (8) \\
\hline Transfer $(\mathrm{T})$ & $d^{-1}$ & $T_{i, j}=f 10_{i, j} \cdot f 11_{i, j}$ & (9) \\
\hline Laying (L) & $d^{-1}$ & $\mathrm{~L}_{13, \mathrm{j}}=\mathrm{f} 12_{13 . \mathrm{j}}$ & (10) \\
\hline Hatching $(\mathrm{H})$ & $d^{-1}$ & $H_{1,1}=f 13_{1,1}$ & (11) \\
\hline \multicolumn{4}{|l|}{ Differential equations } \\
\hline \multicolumn{4}{|l|}{ Growth } \\
\hline Eggs $(i=1)$ & & $\frac{d w_{1,1}}{d t}=0$ & (12) \\
\hline N1 to C5 (i = 2 to 12$)$ & & $\frac{\mathrm{dW}_{1, j}}{\mathrm{dt}}=\mathrm{G}_{i, j}$ & (13) \\
\hline Adults $(i=13)$ & & $\frac{d W_{13 . j}}{d t}=G_{13 . j}-M R_{13 . j}$ & (14) \\
\hline \multicolumn{4}{|l|}{ Dynamics } \\
\hline Eggs $(i=1)$ & & $\frac{d N_{1,1}}{d t}=L_{13, j} \cdot N_{13, j}-\left(H_{1,1}+M_{1,1}\right) \cdot N_{1,1}$ & (15) \\
\hline N1 (1st age class) & & $\frac{d N_{2,1}}{d t}=H_{1,1} \cdot N_{1,1}-\left(T_{2,1}+M_{2,1}\right) \cdot N_{2,1}$ & (16) \\
\hline N2 to C5 (1st age class) & & $\frac{d N_{i, 1}}{d t}=\sum_{j=1}^{n} T_{i-1, j} \cdot N_{i-1, j}-\left(T_{i, 1}+M_{1,1}\right) \cdot N_{i, 1}$ & (17) \\
\hline N1 to C5 (next age class) & & $\frac{d N_{i, j}}{d t}=-\left(T_{1, j}+M_{1, j}\right) \cdot N_{i, j}$ & (18) \\
\hline Adults (1st age class) & & $\frac{d N_{13,1}}{d t}=\sum_{j=1}^{n} T_{12, j} \cdot N_{12,1}-M_{13,1} \cdot N_{13,1}$ & (19) \\
\hline Adults (next age classes) & & $\frac{\mathrm{dN}_{13,1}}{\mathrm{dt}}=-\mathrm{M}_{13,1} \cdot \mathrm{N}_{13, \mathrm{j}}$ & $(20)$ \\
\hline
\end{tabular}

which stay too long in one stage, therefore, the model must simulate a stabilization of growth, hence a growth rate of zero. As the model takes into account critical moulting weights during ontogenic development (see Carlotti \& Sciandra 1989), function f4 limits ingestion when this weight is reached (Hypothesis 3). This phenomenon is hypothetical, as is its mathematical formulation. We assume that ingestion in one stage follows a negative parabolic function (Fig. 3D) when the weight exceeds the critical moulting weight of stage $i: X_{1}$. To avoid introducing an additional coefficient, we decided that function $\mathrm{f} 4$ would cross the abscissa at the weight corresponding to the critical moulting weight of the subsequent stage. This hypothetical function is obviously an important one in the model, both for physiological processes and for population curves, and we discuss below its biological significance.

Two kinds of losses were distinguished in the model: those proportional to the ingestion rate (feces, activity, metabolism) and those related to routine metabolism, which are considered proportional to weight (Fig. 3E to G). We assume that egested matter (f5) is a constant ratio of ingested matter (Fig. 3E). Although the allometric relation of excretion or respiration to weight is frequently used (Ikeda 1974, Conover 1978), we do not introduce it directly. We suppose that it operates through the ingestion function $f 7$ (Fig. 3G). However, even when ingestion is low or equal to 


\section{Ingestion}

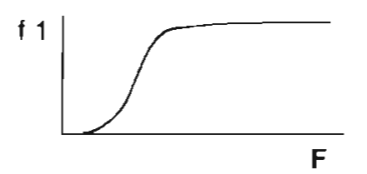

$f 1_{i, j}=P 1_{i} \cdot\left(1-e^{-P 2 i} \cdot F\right)^{P 3_{i}}$

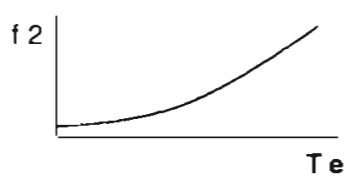

$f 2_{i, j}=P 4_{i} \cdot p 5_{i} \mathrm{Te}$

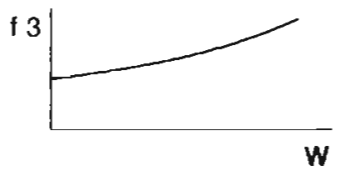

$B_{i, j}=\mathbf{w}_{i, j} P G_{i}$

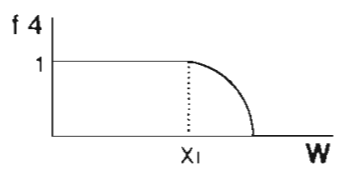

$f 4_{i, j}=1$

$$
=1-\frac{\left(\mathbf{W}_{\mathrm{i}, \mathrm{j}}-\mathrm{X}_{\mathrm{i}}\right)^{2}}{\left(\mathrm{X}_{\mathrm{i}+1}-\mathrm{X}_{\mathrm{i}}\right)^{2}} \quad \text { if } \mathbf{W}_{1, j} \geq \mathrm{X}_{\mathrm{i}}
$$

Fig. 3. Mathematical curves and formulations of copepod physiological relationships and population dynamics terms used in the model. (A) Influence of food concentration on ingestion following an Ivlev curve. (B) Influence of temperature on ingestion. (C) Allometric relation of ingestion with weight. (D) Limitation of ingestion as moulting weight is reached. (E) Fraction of ingested matter not assimilated. (F) Excretion from routine metabolism. (G) Excretion from active metabolism. (H) Influence of weight on the amount of matter invested for reproduction. (I) Influence of specific growth rate on mortality. (J) Weight influence on transfer rate. (K) Cumulated specific growth influence on transfer rate. (L) Laying rate influenced by matter invested for reproduction. (M) Influence of temperature on hatching rate $\mathrm{i}$ : stage; $\mathrm{j}$ : age class; $\mathrm{X}_{1}$ : critical weight for transfer in stage $i_{i} X_{13}$ : critical weight for reproduction; $P 1$ to $P 19$ : biological parameters [see Table 3 in Carlotti \& Sciandra (1989) for definitions]

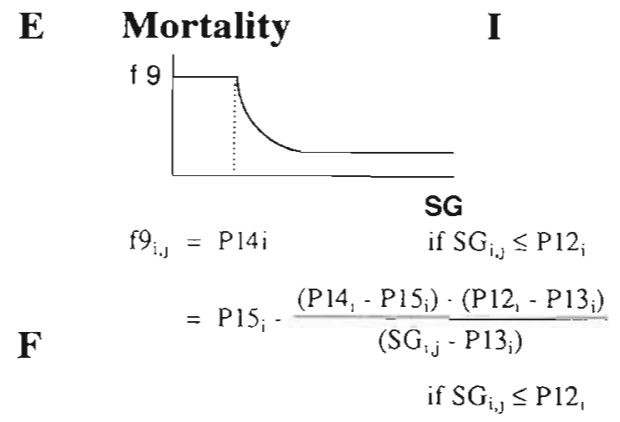

Transfer

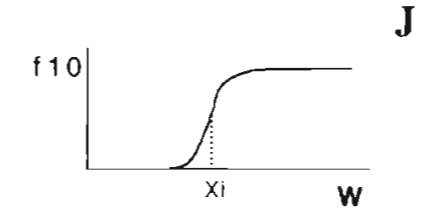

$f 10_{i, j}=\frac{W_{i, j}^{P 16 i}}{\left(W_{i, j}^{P 16 i}+X_{i}{ }^{P 16 i}\right)}$
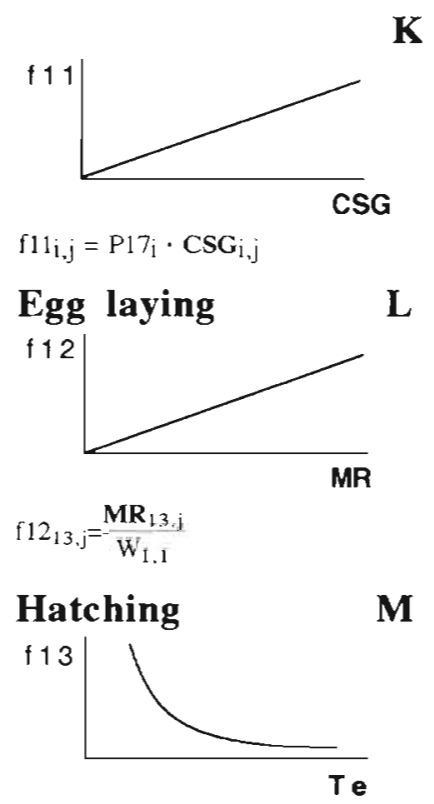

$\left\{13_{1.1}=\left(\begin{array}{ll}P 18_{1} & P 19_{1}^{\mathrm{Te}}\end{array}\right)^{-1}\right.$ zero, the animal must maintain minimum metabolic processes, i.e. basic metabolism and 'routine' metabolism, in order to survive. Wroblewski (1984) uses a constant term, but the function f6 (Fig. 3F) proportional to weight (Corkett \& McLaren 1978) seems to us more appropriate.

By combining functions $\mathrm{f} 1$ to $\mathrm{f} 7$, we obtain the distribution of consumed matter among the different bioenergetic processes at different food levels for a nauplius II with a given weight (here, $0.78 \times 10^{-3} \mu \mathrm{g}$-at. N) and at a constant temperature (Fig. 4A). This type of partitioning is well known for zooplanktonic grazers (see Fig. 2 in Checkley 1985). The consumed matter is not used entirely for growth. There is a threshold food concentration below which the growth rate is negative. In the case of nauplius II, we find that all processes stay more or less constant beyond $8 \mu \mathrm{g}$-at. $\mathrm{Nl}^{-1}$. Fig. $4 \mathrm{~B}, \mathrm{C}$ shows the budget partitioning in the likely weight range of nauplii II of Euterpina acutifrons for 2 food concentrations, one high $\left(13 \mu \mathrm{g}\right.$-at. $\left.\mathrm{N}^{-1}\right)$ and one low (2 $\mu \mathrm{g}$-at. $\mathrm{N} \mathrm{l}^{-1}$ ). For both concentrations all processes, including growth, increase slightly up to a limit situated just above the critical moulting weight (around $0.8 \times 10^{-3} \mu \mathrm{g}$-at. $\mathrm{N})$. Beyond this limit, the ingestion decrease induces a 

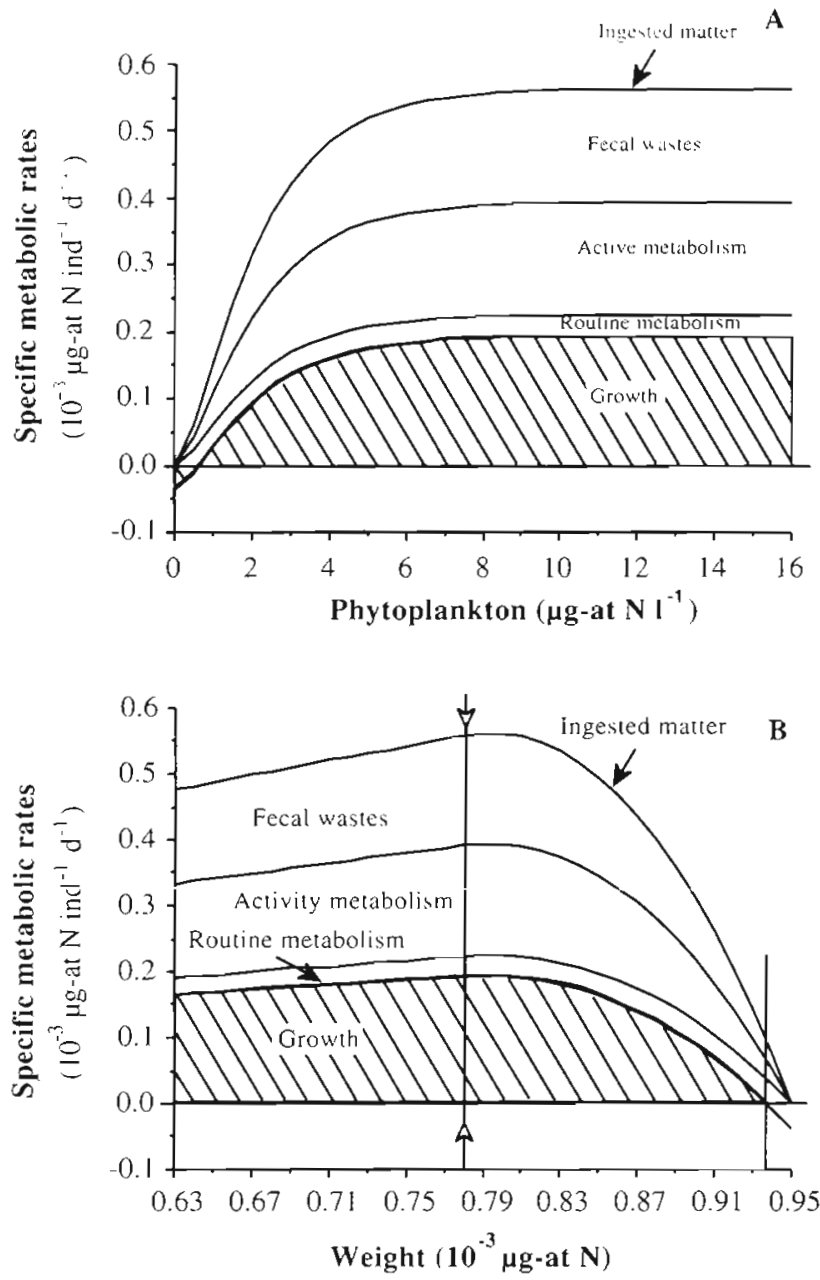

decrease of activity and feces production, whereas the basic losses remain constant. When growth rate reaches zero, weight is at a standstill.

In our model, eggs are laid at the expense of somatic growth; this is a usual pattern in copepods with few reserves (Kiørboe et al. 1985, Berggreen et al. 1988). We have introduced a function representing the matter invested in egg laying as a function of weight (Fig. $3 \mathrm{H}$ ). We used a sigmoidal function (Hill's function), which has in fact been observed in female crustaceans (Corkett \& McLaren 1969, Smith \& Lane 1985, Dailey $\&$ Ralston 1986). The coefficient P10 corresponds to the maximum amount of matter a female can invest in egg laying. For a given weight, function $f 8$ presents the amount of matter to be invested in reproduction. As this amount is taken out of the budget, it limits the gain in weight. The animal's weight is stabilized when the whole material budget is used for reproduction (Fig. 5) Two conclusions can be drawn from this simple scheme: (1) the higher the budget (in Fig. 5, as a function of temperature), the more important is the amount of organic matter invested in egg laying; and conse-

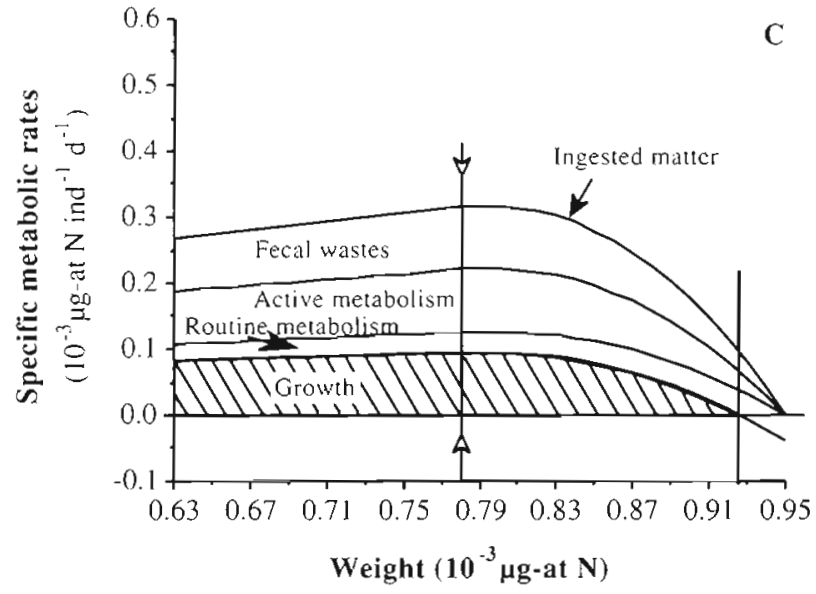

Fig. 4. Utilization of ingested matter by copepods at different food concentrations (A) and according to the animal's weight in a given stage (here a Nauplius II of Euterpina acutifrons)

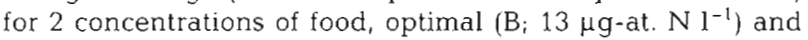
limiting ( $C ; 2 \mu \mathrm{g}$-at. $\mathrm{N}^{-1}$ ). In (A), temperature and copepod weight are fixed. Wastes trom metabolism are divided into routine metabolism and active metabolism; the second type takes into account filtering activity and specific dynamic action. In (B) and $(\mathrm{C})$, beyond the critical moulting weight (here $0.78 \mu \mathrm{g}$-at. N), the influence of function $\mathrm{f} 4$ induces a diminution of ingested matter and, as a consequence, of the growth rate. The fastest individuals only undergo the first part of the growth curve. After the critical moulting weight, they moult towards the next instar. For the other ones, when growth rate is zero, weight becomes constant

quently (2) the weight of eggs laid by females stabilizes at a higher value.

\section{Processes of population dynamics}

Mortality rate is usually considered as constant for the population as a whole. In fact, though, it varies according to growth stage (Paffenhöfer 1970), and within each stage, according to the physiological condition of the organism. In recent models of population dynamics of zooplanktonic organisms, some authors have introduced mortality functions which depend on the ingestion rate (Davis 1984, 1987) or on the material budget (Wroblewski 1984). We used an increasing hyperbolic function (Fig. 31), which allows for a high mortality rate when budgets are unfavourable and a low mortality when they are favourable (Hypothesis 1).

Moult determination is complex, but it is reasonable to believe that moulting occurs only when a set of fundamental biological conditions are combined. Two factors were distinguished (Hypothesis 2). In our 

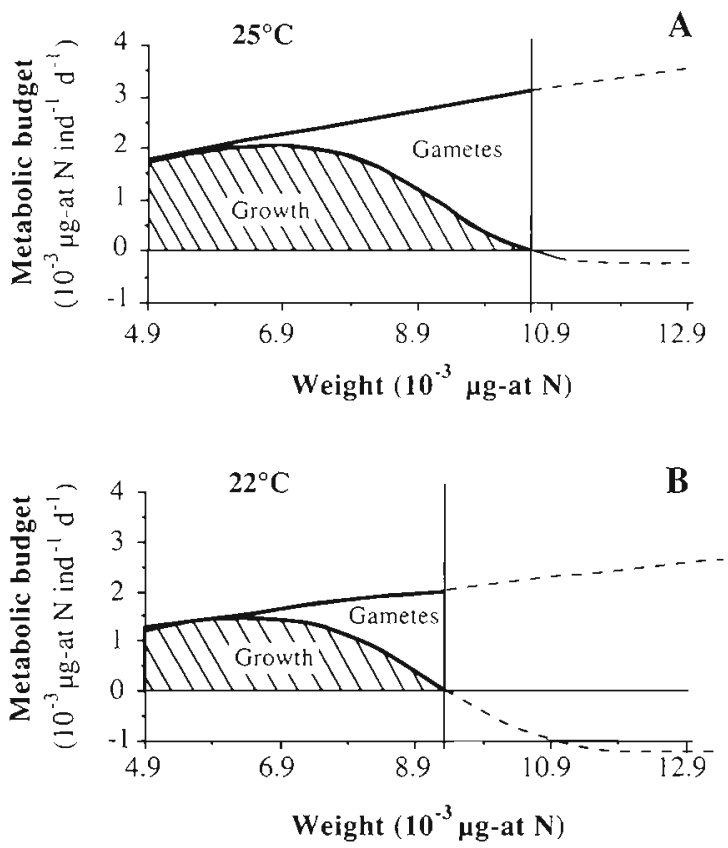

Fig. 5. Transition of budget investment from growth to reproduction as a function of copepod weight. When growth is zero, the animal's weight stops increasing and the egg-laying rate is constant. Such a representation enables a greater egglaying rate when the budget increases (here under the effect of temperature). (A) $25^{\circ} \mathrm{C} ;$ (B) $22^{\circ} \mathrm{C}$

model, the transfer rate from one stage to the next (i.e. moulting) depends first of all on weight (Fig. 3J). We suppose that the animals can moult from stage i to stage $\mathrm{i}+1$ only after having reached a critical weight $\mathrm{X}_{\mathrm{i}}$ (function $\mathrm{f} 10$ ). On the other hand, moulting also depends on the physiological condition of the organisms, and we assume that the material budget provides a good indication of these conditions (function f11). As the moulting rate is not immediately influenced by variations in external patterns we used an average value of the instantaneous budgets for the hours immediately preceding moulting (Fig. 3K), which represents accumulated energy or an energy deficit, as explained in Nival et al. (1988).

Egg-laying rate depends directly on the matter invested for reproduction at any time (Fig. 3L). The eggs are assumed to have the same weight, to be physiologically equivalent, and without any phenomenon of ageing or loss of ability to hatch. Consequentiy, the hatching rate (Fig. 3M) is considered to be the inverse of embryonic duration, controlled by temperature (McLaren et al. 1989.)

Regarding simulations, we will discuss the influence of the 3 underlying hypotheses on the functioning of population dynamics and theirs links with physiological processes.

\section{SIMULATIONS}

The simulations presented here complement those given by Carlotti \& Sciandra (1989) and the coefficient values remain unchanged (see their Table 3). The system of differential equations is solved by a fourthorder Runge-Kutta numerical integration with a time step of $1 \mathrm{~h}$.

\section{Time course of processes as a function of age of individuals within a stage}

Fig. 6 shows the dynamics of the developmental stages of a Euterpina acutifrons population beginning with 100 eggs, in optimal conditions $\left(22^{\circ} \mathrm{C}\right.$ temperature, $8 \mu \mathrm{g}$-at. $\mathrm{N}^{-1}$ food concentration), for the first generation.

The model can give at any time the rates of the biological processes and the values of state variables in each age class at every stage. Thus a considerable amount of information is obtained rapidly. We have therefore chosen to present the values of the main processes as a function of age within stage for only 2 successive stages. Fig. 7 shows the values of abundance, individual weight, and rates of ingestion, growth, mortality and moulting for each age class of naupliar stages 1 and 2 (NI and NII), at Days 1, 2, 3 and 4 (see Fig. 6).

\section{Day 1}

On Day 1, there are individuals in the first 4 age classes of NI and in the first 3 of NII. At the NI stage, the ' 0.75 ' age class (individuals hatched between ' 0.75 ' and ' $0.5^{\prime} \mathrm{d}$ ) is the most abundant, first because fewer

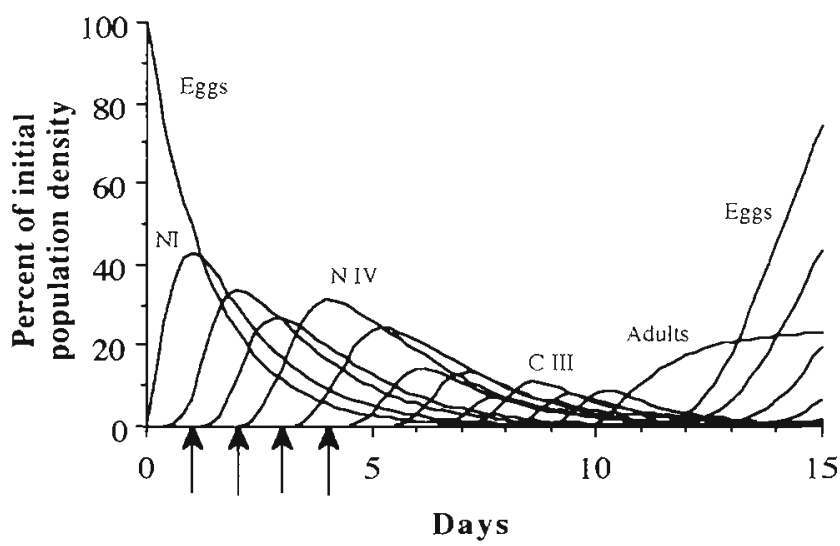

Fig. 6. Euterpina acutifrons. Simulated time courses of stage abundances (eggs, 6 nauplii, 5 copepodites and adults) under constant temperature and food supply $\left(22^{\circ} \mathrm{C}\right.$ and $8 \mu \mathrm{g}$-at $\mathrm{N}^{-1}$ ). The simulation starts with 100 eggs having identical weights $\left(0.5 \times 10^{-3} \mu \mathrm{g}\right.$-at. N) 


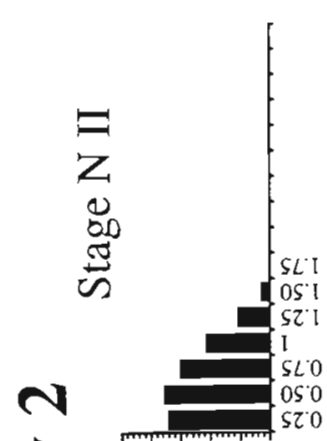

范

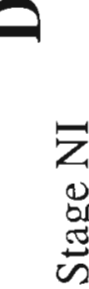

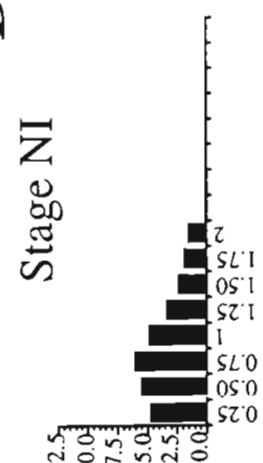

( 1 . poin)

วouepunq

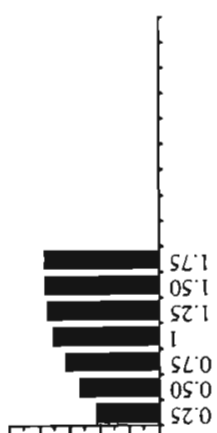

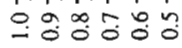
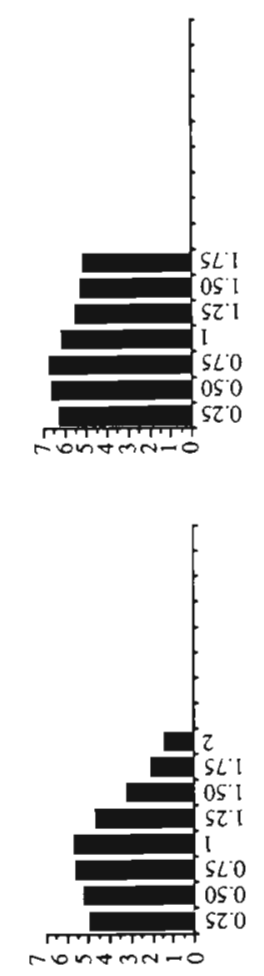

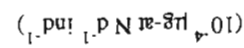

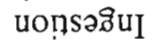
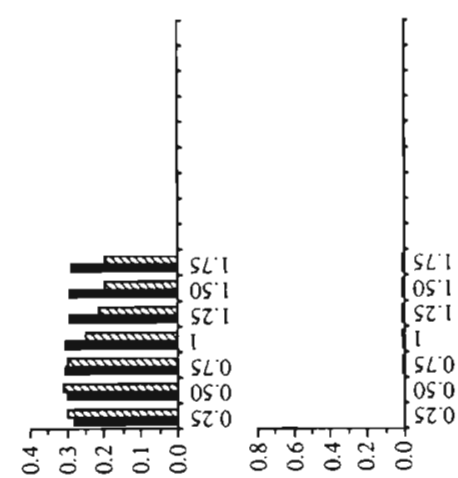

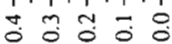
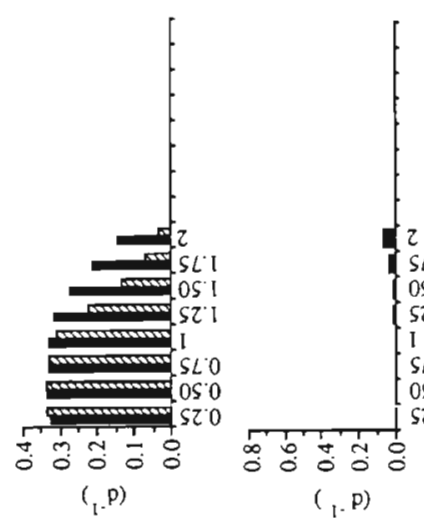

วIE] पมMOID ว|อI KI!โอนกW

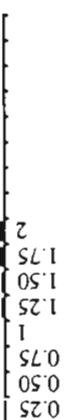

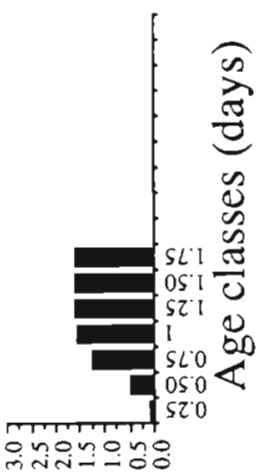
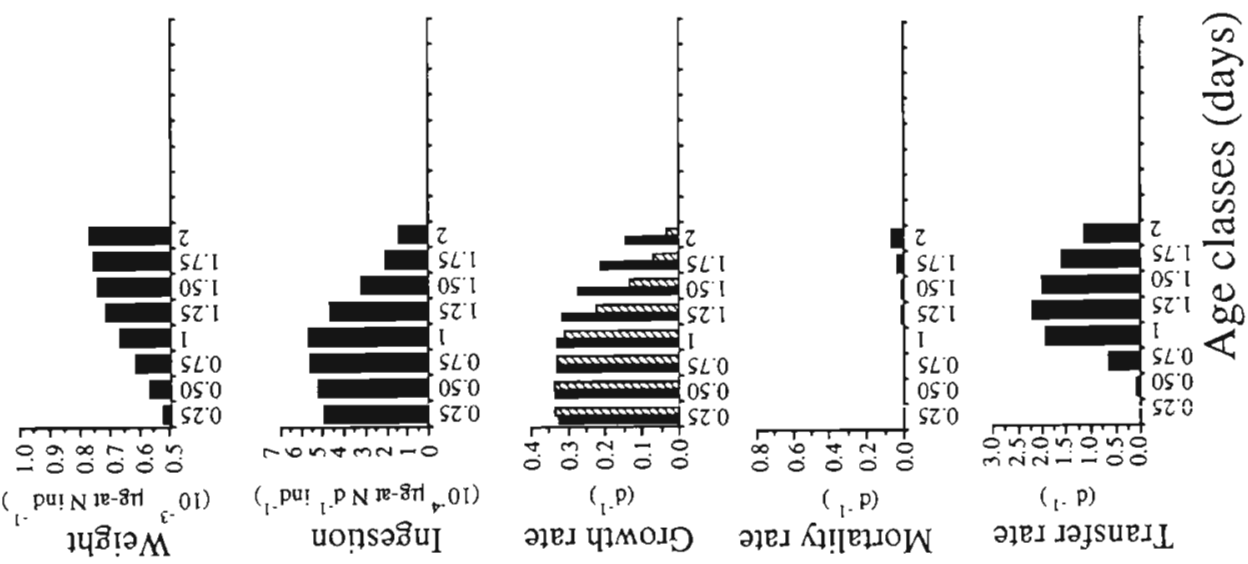

כְשI IOJSURIL
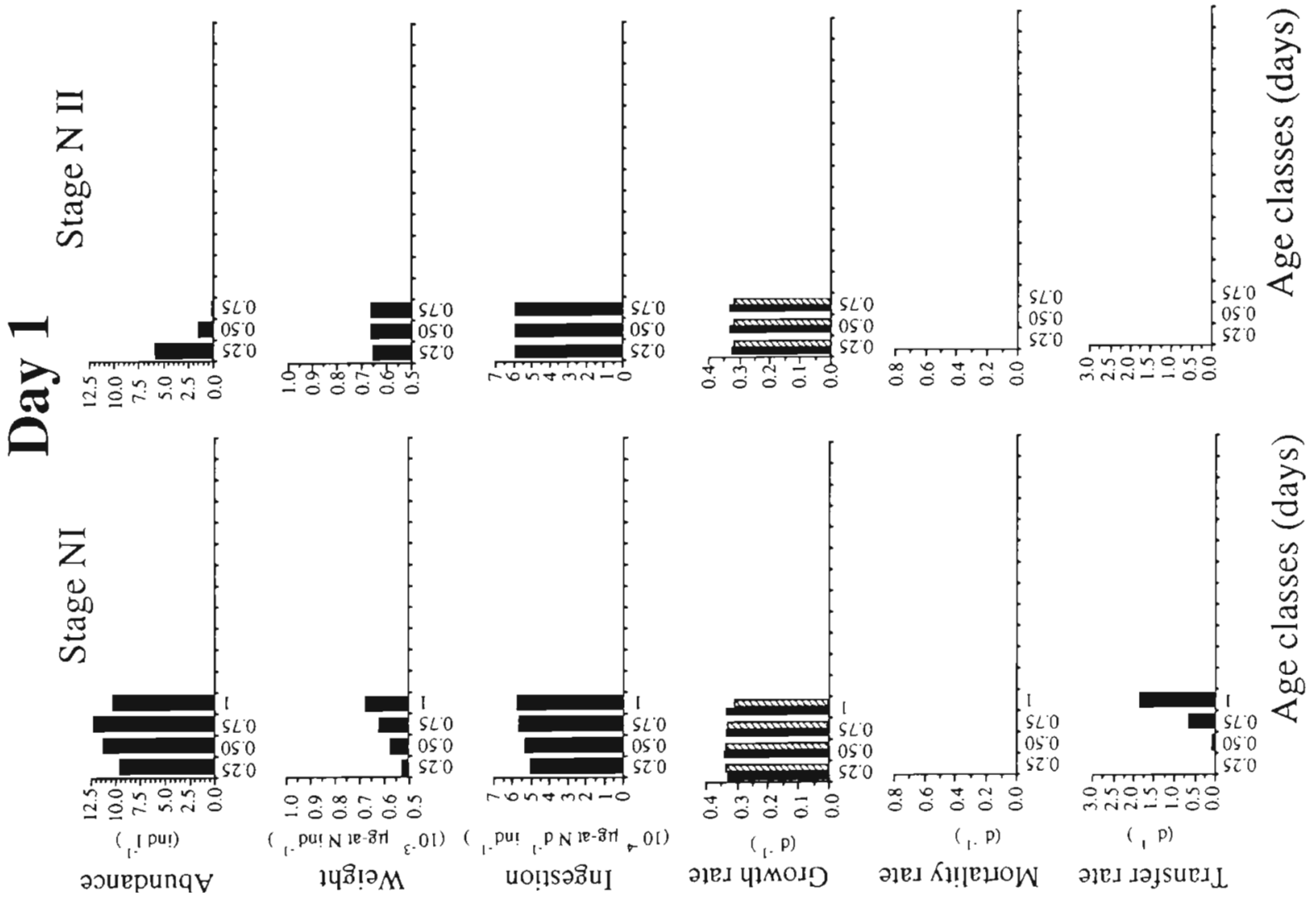

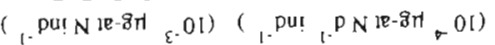

गบฮ์!ว $M$

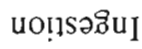

गื. प1MOJP

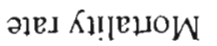

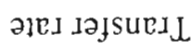



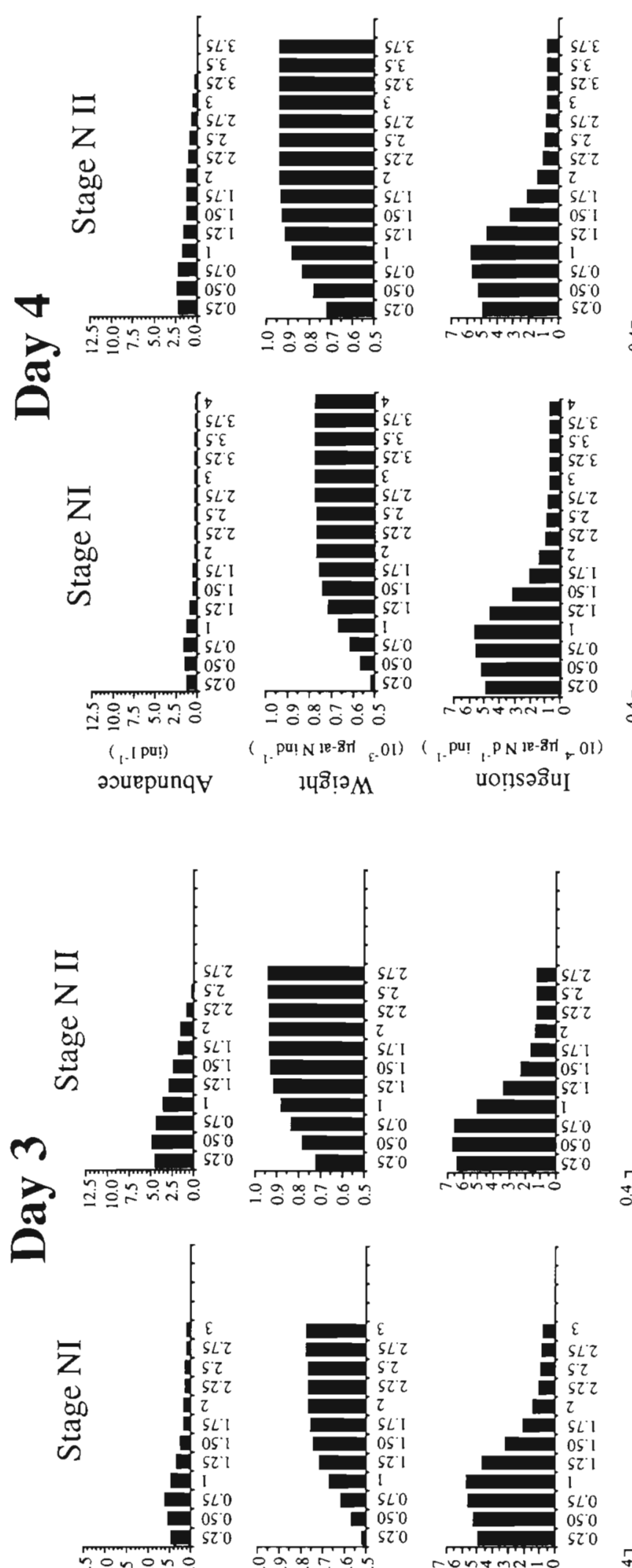

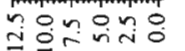
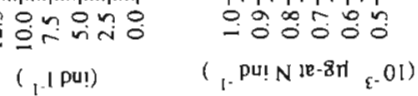

souepunqy

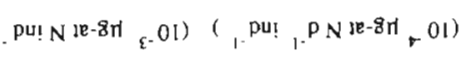

गธริเวM

Uo!! $1528 \mathrm{uI}$
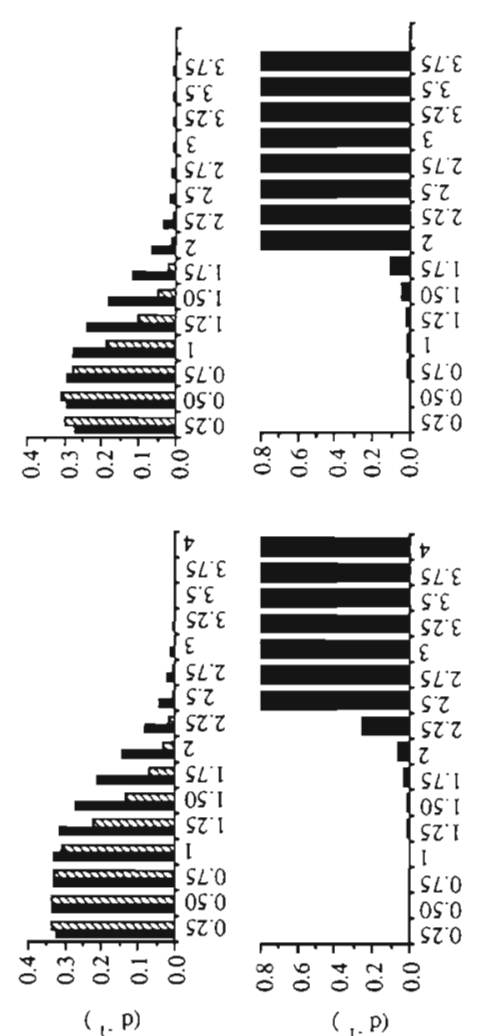

ว]EI पIMOID

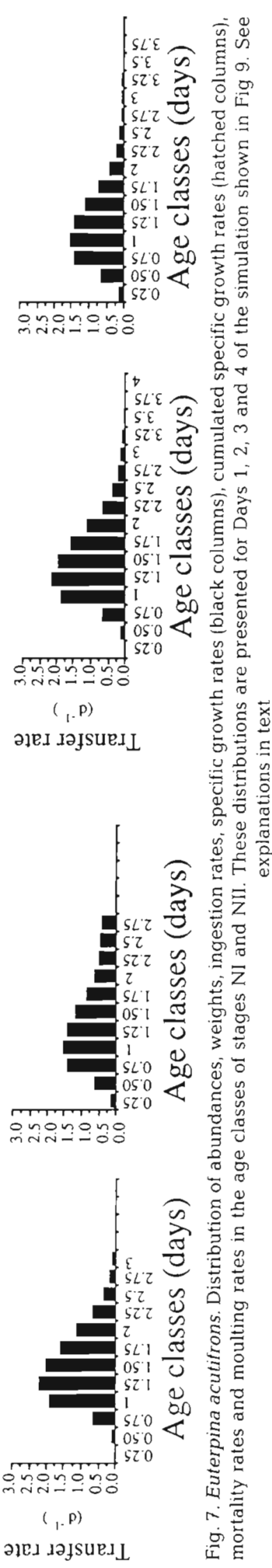


eggs were hatched in age classes '0.25' and '0.5' (see Fig. 7) and second because some individuals in age class ' 1 ' have already molted to stage NII (see transfer rate).

The copepods hatch at stage NI, having the same weight as their eggs (considered as constant), then start growing. Ingestion rate increases with age, but this can only be attributed to weight increase, since the trophic conditions are constant. As ingestion rate shows a negative allometric relationship with weight, the intrinsic growth rate decreases slightly, but still remains quite sufficient for the survival of the copepods, and mortality rates are minimal. In contrast to stage NI, age classes at stage NII have practically the same weights on Day 1 . However, weights upon entering stage NII are different for each of these classes. An individual having moulted precociously to stage NII (i.e. in the ' 0.75 ' age class) has a lower weight at moult than an individual which has just moulted on Day 1. Nevertheless, most of the individuals of age class ' 0.25 ' in NII (just moulted) issue from age class ' 1 ' of NI, so the weights of individuals in these 2 classes are similar.

In other words, the earlier the individuals enter stage NII, the lower is their weight, but the amount of matter which has not been gained in one stage is gained in another. This phenomenon also occurs for growth and metabolic rates. Mortality and transfer rates are zero because NII individuals weigh less than the critical moulting weight and metabolic rates are high.

\section{Day 2}

For each time interval of $0.25 \mathrm{~d}$, the individuals of a given class, with all their characteristics, transfer to the next age class. From Day 1 to Day 2, 4 new age classes appear at each stage (NI and NII), shifting the ' $0.25^{\prime}$ to ' 1 ' age classes of Day 1 to ' 1.25 ' to ' 2 '. This shows that abundances spread among age classes at stage NI, owing to egg-hatching and the moulting of old individuals within a stage. Whereas there is a gain in weight with young age classes, the weights of the old individuals within a stage reach a maximum. These individuals have overlapped the critical moulting weight and their growth and ingestion rates decrease rapidly, due to function 44 (see Hypothesis 3). Consequently, the oldest age classes show some mortality (see Hypothesis 1). The moulting rate decreases more gradually, as it is related to the cumulative growth rate over the preceding hours (see Hypothesis 2), and not to the instant growth rate.

In stage NII, the most recently recruited age classes ('0.25' to ' 1 ') are more abundant than classes ' 1.25 ' to ' 2 '. The total number of NII nears a maximum on Day 2 (see Fig. 6). The weight in the first class at stage NII ('0.25') has shifted towards an opti- mal value, due to the new age structure in stage NI (compare Days 1 and 2).

Age classes '0.25' to ' 1 ' show a linear increase in weight. The first age classes ('1.25' to ' 2 ') reach the critical moulting rate to stage NIII and their metabolic rates start decreasing. However, the growth rate stays very high and the transfer rate is maximum, whereas mortality is zero.

\section{Days 3 and 4}

The tendencies observed on Day 2 are confirmed: the abundances of age classes keep spreading, due to the fact that hatchings become scarcer. The weight histograms show the growth phase of the individuals as they enter a given stage, followed by their stabilization. When the organisms weigh more than the critical weight for moulting to the next stage, their ingestion rate decreases to the minimum needed to balance the basic needs, and instant growth rate falls to zero (combination of Hypotheses 1, 2 and 3). As a result, the probability of death rises and the probability of moulting (transfer to the next instar) diminishes more and more.

\section{Time course of processes for a complete instar}

Most of the time, laboratory experiments, conceived to determine biological processes, are conducted on whole populations. We were able to represent this with the model (all the age classes of a stage were grouped together and we obtained mean values for the processes). Fig. 8 shows the time courses of mean rates of ingestion, growth, mortality and moulting. The curves are a combination of these various rates and of abundance values for age classes. As there are always some individuals in each age class, the mean rates decrease slowly.

\section{Time course of processes for a population with a stable structure}

A 100 d simulation of Euterpina acutifrons population dynamics showed that variability in development of individuals results in a progressive distribution of the individuals among all stages (Fig. 9A). In a steady environment, therefore, the population shows a stabilization of its age structure. In other words, the frequencies of the various stages become constant. During the first $40 \mathrm{~d}$, fluctuations in abundances marked the successive stages, owing to the initial condition (i.e. egglaying was synchronous). Four generations are easily distinguishable, but after that are difficult to detect. Zurlini \& Ferrari (1979) cultivated E. acutifrons over 

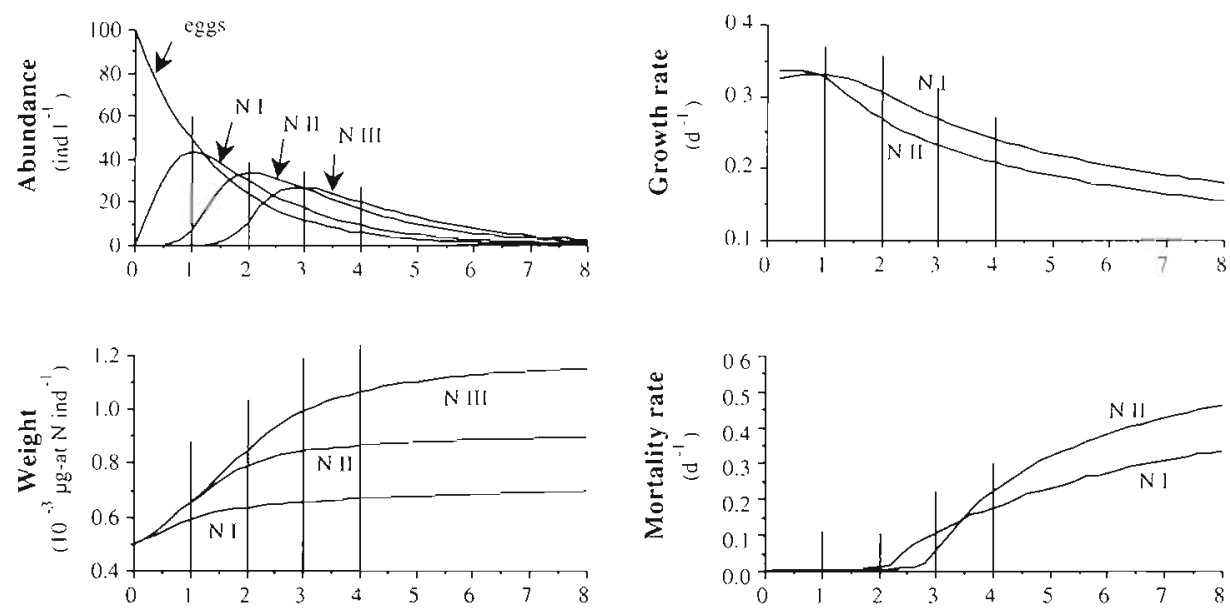

Fig. 8. Euterpina acutifrons. Time courses of average values of abundance, weight, ingestion rate, specific growth rate, mortality rate and moulting rate, at stages NI and NII. At any time, each curve corresponds to the average of age class values
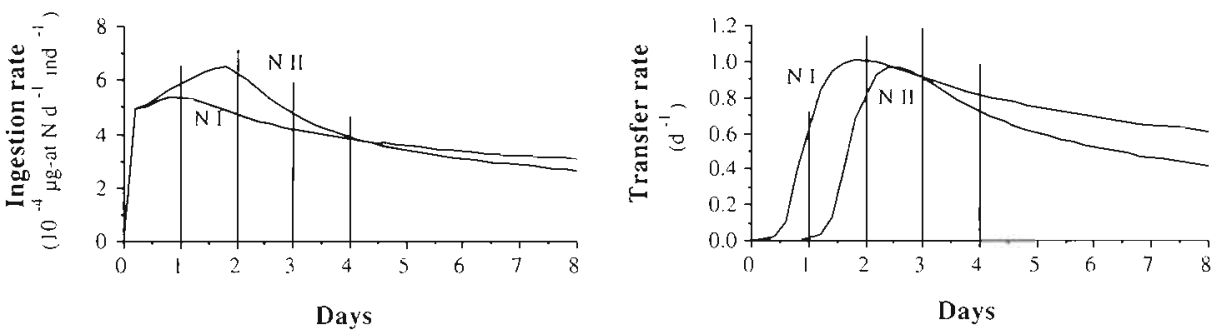

several generations, at $18^{\circ} \mathrm{C}$, starting with 3 mature females. The population structure also stabilized after $60 \mathrm{~d}$ and at the fourth generation.

We focused on the time course of processes during the first 2 naupliar stages between Days 58 and 60, i.e. when the age structure of the population begins to stabilize (Fig. 10). With the model, we can take a 'snapshot' of all the processes in each age class of NI and NII. The profiles of metabolic rates and of moulting and mortality rates are obtained as a function of age in stages NI and NII, and are similar to those already observed and commented on during the first days (see Fig. 7). At Day 60, the age structure is still the same, although absolute abundances have increased. Other variables and processes keep the same values as on Day 58 in all age classes.

The constancy of the age structure induces a constant rate of processes for each stage. Let $N_{1, j}(t)$ be the number of individuals of class $j$ in stage $i$ at time $t$, and $N_{i, j}(t+1)$
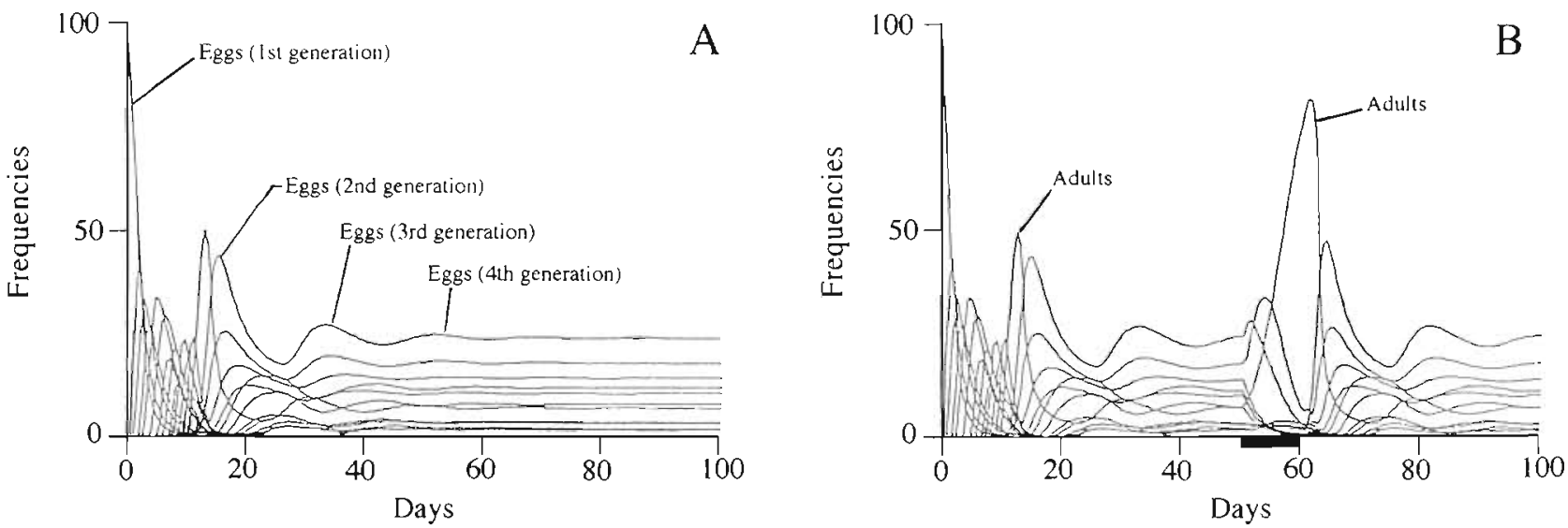

Fig. 9. Euterpina acutifrons. (A) Time course of the stage structure (\%) in the population over 100 d. Relative abundances of stages in the whole population become constant after the 4 th generation, i.e. 60 d. Food and temperature values are those of the simulation in Fig. 6. (B) Effect of food deprivation (heavy horizontal line) between Days 50 and 60 on the population structure; the stability of the population structure is perturbed. In situ, such variability in external parameters would continuously perturb the population structure 


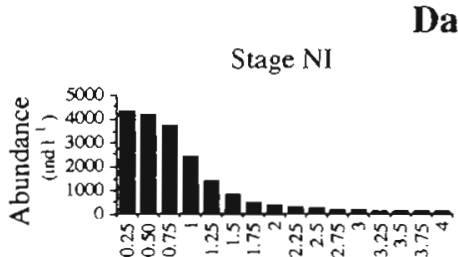

Day 58
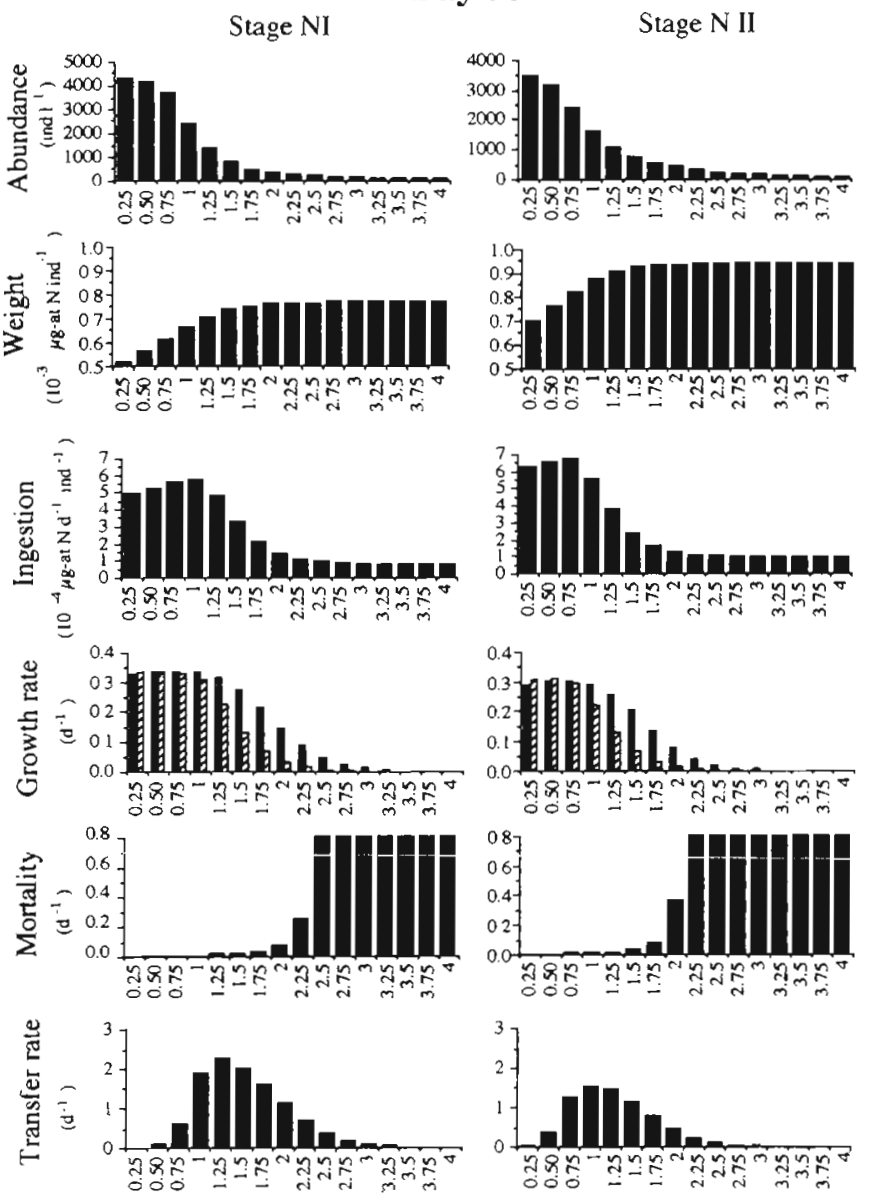

Age classes (days)

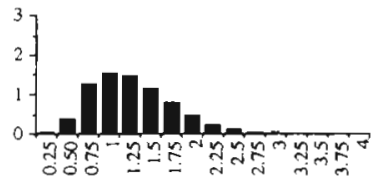

Age classes (days)

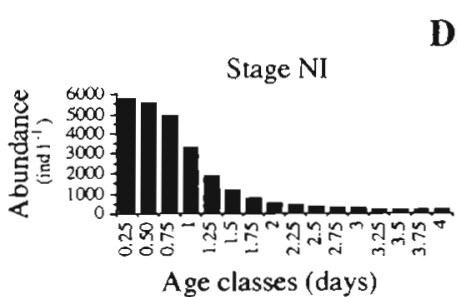

Day 60

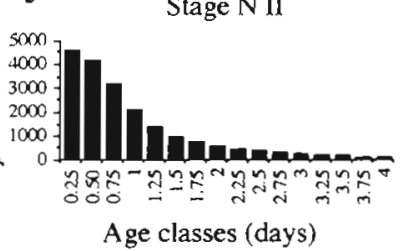

Fig. 10. Euterpina acutifrons. Distribution of abundances, weights, ingestion rates, specific growth rates (black columns), cumulated specific growth rates (hatched columns), mortality rates and moulting rates among the age classes of stages NI and NII, at Day 58. Abundances at Day 60 are higher than at Day 58 , but relative abundances of each age class are the same

the equivalent number at time $t+1$. Let $P$ be a given biological process (e.g. ingestion, respiration) influenced by environmental variables (food, temperature) but not by demography, and let $P_{i, j}(t)$ and $P_{1, j}(t+1)$ be the values of this process $P$ at times $t$ and $t+1$. When the population structure is steady, $N_{i, j}(t+1)$ is proportional to $N_{i, j}(t)$ and $P_{i, j}(t)$ is constant; thus the average biological process $P_{i}$ in stage $i$ at time $t+1$ is expressed as follows:

$$
\begin{aligned}
P_{1}(t+1) & =\frac{\sum_{j=1}^{n} P_{i, j}(t+1) \cdot N_{1, j}(t+1)}{\sum_{j=1}^{n} N_{i, j}(t+1)} \\
& =\frac{\sum_{j=1}^{n} P_{i, j}(t+1) \cdot \alpha N_{i, j}(t)}{\sum_{j=1}^{n} \alpha N_{1, j}(t)}=P_{i}(t),
\end{aligned}
$$

where $\alpha$ is a constant. This clearly shows that, if environmental conditions remain constant, the average rates of processes at each stage are stable, due to the steady state of the population structure, but rates of individual processes vary according to the age class.

\section{DISCUSSION}

A process observed at the population level is the result of the physiology of individuals, which depends on external (food, temperature, etc.) and internal (ageing, etc.) parameters, and on the asynchronous development of individuals, a phenomenon linked with the dynamics of the population.

Thus the model can be used as a tool for interpreting the mean values of processes at the population level (Fig. 8) with the events at the individual level (Fig. 7). It describes the time course of the processes throughout an individual's life and the variability in the individual's growth. In optimal conditions, most of the individuals grow until they reach the critical moulting weight at each stage, and then moult. Owing to function $\mathrm{f} 3$, these individuals show exponential growth throughout the development from egg to adult (see Fig. 4 in Carlotti \& Sciandra 1989). They therefore do not show a decrease in ingestion. Some copepods do not moult immediately upon reaching the critical weight. Their growth is reduced, because of decreased ingestion (Hypothesis 3), and their development is delayed (Hypothesis 2), or they can even die (Hypothesis 1).

In sub-optimal conditions, only a few copepods display normal development, but for most of them, the moult is slower and more difficult. For them, growth may not be exponential and mortality rate is high. Thus the model explains an important experimental finding: why is it that exponential growth can be observed in optimum conditions (McLaren 1986) but not in limiting conditions (Miller et al. 1977)?

The significance of Hypothesis 3, which assumes a decreased ingestion when the copepod is about to moult to the next stage (function $\mathrm{f} 4$ ), is supported by the model. Under favourable conditions, this decrease only lasts a very short time, after which most of the animals moult rapidly and resume normal feeding. On 
the other hand, when conditions are poor, this process plays an important role. It prevents an abnormal weight increase in the organisms which do not moult and consequently increases their death rate as grazing decreases. For decapods, which are easier subjects for the study of moulting processes, it has been shown that ingestion stops during moult (Lasker 1966, Harpaz et al. 1987, Anger et al. 1989), because mandibular appendages and the exoskeleton, which is part of the digestive tract, are replaced. Anger \& Dietrich (1984) even observed that ingestion decreases early in the intermoult phase, and they adjusted the maximal ingestion rate as a function of age, by means of a decreasing parabola (see also Fig. 1 in Anger 1990). Regarding copepods, some isolated observations of individuals close to moulting describe a stoppage of filtration and ingestion before and during the moult (Paffenhöfer 1971, Harris \& Paffenhöfer 1976), but there has been no clear demonstration of this. It is perhaps difficult to show experimentally such a decrease in ingestion by copepods, since presumably the individuals are not synchronously influenced by it. The ingestion rate should therefore be measured continuously on isolated animals.

Thus, variability of development within a cohort can be explained by the model: some individuals develop at a maximum rate throughout their existence, and others delay development to a variable extent. This has been clearly observed in experiments (Carlotti \& Nival 1991).

Among the variables shown in Fig. 8, the only one frequently found in the literature is transfer rate. This is in fact easy to determine experimentally, by taking individuals recently moulted into a stage and measuring the time until they moult to the next one. The moulting rates obtained here by simulation are similar to experimental results (Sulkin \& Van Heukelem 1986, Carlotti \& Nival 1992). Thus the model suggests a deterministic explanation for the shape of this curve. The transfer rate depends on the weight of organisms and their physiological state (Hypothesis 2). The ascending part of the curve is the consequence of a rapid increase in the probability of moulting beyond the critical moulting weight The decreasing portion is the result of a progressive loss of the ability to moult, which has a physiological basis (ageing). If an individual stays too long in a stage, its growth rate decreases (due to Hypothesis 3), its weight does not increase, and the probability of dying increases (due to Hypothesis 1).

Under such conditions, from the modeller's point of view, it is not necessary to have a large number of age classes at each stage (see Fig. 2), and it is quite justifiable to group in a last age class those individuals with similar characteristics which will play no further part in the development of the population.
At any time, the population structure has an influence on the overall mean value of processes or variables (weight, etc.), which makes it difficult to obtain information on these processes and variables at specific levels. The only way to improve our knowledge of the processes is to observe the organisms individually, or a very closely clustered cohort, i.e. to disturb the steady state and study the dynamics of a cluster of individuals.

However, processes or variables inaccessible to the experimenter may exist, such as a decrease in ingestion (f4), because their fluctuations are hidden by other processes, or even by individual variability. They are then omitted from the conceptual schemes drawn from experimentation. A mathematical model can offer conceptual diagrams of functional relationships which govern growth and development phenomena and can test them.

The pattern suggested by the model for mortality rate as a function of age seems quite new. It results from the relationship between mortality rate and growth rate (Hypothesis 1) and from the decrease of ingestion (Hypothesis 3) beyond the critical moulting weight. We have confirmed experimentally the increase of mortality with age within stage (Carlotti \& Nival 1992).

When the development of a population under optimal conditions of temperature and food is simulated (see Fig. 9A), the percentages of the abundance of individuals in the various stages tend towards steady values, and the population structure is stabilized. If a temporary low concentration of food is simulated (Fig. 9B), the population structure is immediately disturbed; afterwards it tends to return to a steady structure once again. In the marine environment, this sort of disturbance is very frequent, and the population cannot be represented by a mean individual with constant rates of biological processes (see Båmstedt 1988).

Most ecosystem models use constant values and do not take into account population dynamics, which have a strong influence on the dynamics of the ecosystem (Hassel \& May 1985). Yet it is necessary to take into account the population level, between the individual and the ecosystem, as has been pointed out previously [Marine Zooplankton Colloquium 1 (1989); see also De Angelis (1988)]. The difficulty lies in setting up the real rules connecting the individual, the population and the ecosystem. Our model, which couples individual growth and population dynamics, can simulate values of processes steady in time if the external conditions are also steady, though potentially it maintains the ability to express the internal dynamics of the system if the environment is suddenly disturbed. 
Acknowledgements. This work was part of a doctoral thesis at the University of Paris 6 (Carlotti 1990), supported by CNRS/UA 716. We thank S. Nival, who has generously helped in various ways, $Q$. Bone for comments on an earlier draft, and M. Delahaye for improving the English. We extend our gratitude to the anonymous reviewers for their constructive comments; 2 of them were particularly helpful in editing the manuscript.

\section{LITERATURE CITED}

Anger, K. (1990). Modelling of developmental changes in the carbon and nitrogen budgets of larval brachyurian crabs. Helgoländer wiss. Meeresunters. 44: 53-80

Anger, K., Dietrich, A. (1984). Feeding rates and gross growth efficiencies in Hyas araneus L. larvae (Decapoda: Majidae) reared in the laboratory. J. exp. mar. Biol. Ecol 77: $169-181$

Anger, K., Harms, J., Püschel, C., Seeger, B. (1989). Physiological and biochemical changes during the laravl development of a brachyuran crab reared under constant conditions in the laboratory. Helgoländer wiss. Meeresunters. 43: $225-244$

Båmstedt, U. (1988). Ecological significance of individual variability in copepod bioenergetics. Hydrobiologia $16 \bar{f} / 168: 43-59$

Berggreen, V., Hansen, B., Kiørboe, T. (1988). Food size spectra, ingestion and growth of the copepod Acartia tonsa during development: implication for determination of copepod production. Mar. Biol. 99: 341-352

Cale, W. G. (1988). Characterizing population as entities in ecosystem models: problems and limitations of massbalance modelling. Ecol. Modelling 42: 89-102

Carlotti, F. (1986). Modèle de recrutement de larves d'organismes marins. Influence de la nourriture et des prédateurs. D. E. A. d'Océanographie Biologique, Université Paris

Carlotti, F. (1987). Modèles de recrutement de larves d'organismes marins. J. Rech. océanogr. 12: 12-16

Carlotti, F. (1990). Modèle de recrutement d'espèces marines. Couplage du bilan de matière individuel et de la dynamique de population. Thèse de Doctorat de l'Université Pjerre et Marie Curie, Université Paris VI

Carlotti, F., Nival, S. (1991). Individual variability of development in laboratory reared Temora stylifera copepodites: consequences for the population dynamics and interpretation in the scope of growth and development rules J. Plankton Res. 13: 801-813

Carlotti, F., Nival, S. (1992). Moulting and mortality rates of copepods related to age within stage: experimental results. Mar. Ecol. Prog. Ser. 84: 235-243

Carlotti, F., Sciandra, A. (1989). Population dynamics model of Euterpina acutifrons (Copepoda: Harpacticoida) coupling individual growth and larval development. Mar. Ecol. Prog. Ser. 56: 225-242

Checkley, D. M. (1980). Food limitation of egg production by a marine planktonic copepod in the sea off southern California. Limnol. Oceanogr. 25: 991-998

Checkley, D. M. (1985). Nitrogen limitation of zooplankton production and its effect on the marine nitrogen cycle. In Lampert, W. (ed.) Food limitation and the structure of zooplankton communities. Ergeb. Limnol 21: 103-113

Conover, R. J. (1966). Factors affecting the assimilation of organic matter by zooplankton and the question of superfluous feeding. Limnol. Oceanogr. 11: 346-354

Conover, R. J. (1978). Transformation of organic matter. In:
Kinne, O. (ed.) Marine ecology, Vol, 4, Dynamics. Wiley London, p. 221-499

Corkett, C. J., McLaren, I. A. (1969). Egg production and oil storage by the copepod Pseudocalanus in the laboratory. J. exp. mar. Biol. Ecol. 3: 90-105

Corkett, C. J., McLaren, I. A. (1978). Biology of Pseudo calanus. In: Russel, F. S. (ed.) Advances in marine biology, Vol. 15. Academic Press, London, p. 1-233

Dailey, M. D., Ralston, S. (1986). Biological development of Heterocarpus laevigatus. Fish. Bull. U.S. 84: 915-925

Davis, C. S. (1984). Predatory control of copepod seasonal cycles on George Bank. Mar. Biol. 82: 31-40

Davis, C. S. (1987). Components of the zooplankton production cycle in the temperate ocean. J. mar. Res. 45: 947-903

De Angelis, D. L. (1988). Strategies and difficulties of applying model to aquatic populations and food webs. Ecol. Modelling 43: 57-73

Harpaz, S., Kahan, D., Galun, R. (1987). Variability in feeding behavior of the Malaysian prawn Macrobrachium rosenbergii (De Man) during the molt cycle (Decapoda, Caridea). Crustaceana 52: 53-60

Harris, R. P., Paffenhöfer, G. A. (1976). Feeding, growth and reproduction of the marine planktonic copepod Temora longicornis Müller. J. mar. biol. Ass. U.K. 56: 675-690

Hassel, M. P., May, R. M. (1985). From individual behavior to population dynamics. In: Sibly, R. M., Smith, R. H. (eds.) Behavioral erolngy: ecological consequences of adaptative behavior. Blackwell Scientific, Oxford, p. 3-32

Huntley, M. (1988). Feeding biology of Calanus: a new perspective. Hydrobiologia 168: 83-99

Huntley, M., Boyd, C. (1984). Food-limited growth of marine zooplankton. Am. Nat. 124: 455-478

Ikeda, T (1974). Nutritional ecology of marine zooplankton. Mem. Fac. Fish. Hokkaido Univ. 22: 1-97

Ikeda, T (1985). Metabolic rates of epipelagic marine zooplankton as function of both mass and temperature. Mar. Biol. 85: 1-11

Kiorboe, T., Møhlenberg, F., Hamburger, K. (1985). Bioenergetics of the planktonic copepod Acartia tonsa between feeding, egg production and respiration, and composition of the specific dynamic action. Mar. Ecol. Prog. Ser. 26: 85-97

Kiørboe, T., Møhlenberg, F., Nicolajsen, H. (1982). Ingestion rate and gut clearance in the planktonic copepod Centropages hamatus (Lilljeborg) in relation to food concentration and temperature. Ophelia 21. 181-194

Kremer, J. N., Nixon, S. W. (1978). A coastal marine ecosystem. Simulation and analysis. Ecological studies, Vol. 24. Springer-Verlag, Heidelberg

Lasker, R. (1966). Feeding, growth, respiration and carbon utilization of a euphausiid crustacean. J. Fish. Res. Bd Can. 23: 1291-1317

Marine Zooplankton Colloquium 1 (1989). Future marine zooplankton research - a perspective. Mar. Ecol. Prog. Ser. 55: 197-206

McLaren, I. A. (1978). Generation lengths of some temperate marine copepods: estimation, production and implications. J. Fish. Res. Bd Can. 345: 1330-1342

McLaren, I. A. (1986). Is 'structural' growth of Calanus potentially exponential? Limnol. Oceanogr. 31. 1342-1346

McLaren, I. A., Sévigny, J.-M., Corkett, C. J. (1989). Temperature-dependent development in Pseudocalanus species. Can J. Zool. 67: 559-564

Miller, C. B., Johnson, J. K., Heinle, D. R. (1977). Growth rules in the marine copepod genus Acartia. Limnol. Oceanogr. 22: $326-335$

Mullin, M. M., Brooks, E. R. (1970). Growth and metabolism 
of two planktonic marine copepods as influenced by temperature and two types of food. In: Steele, J. H. (ed.) Marine food chains. Univ. Calif., Berkely, p. 74-95

Mullin, M. M., Brooks, E. R. (1976). Some consequences of distributional heterogeneity of phytoplankton and zooplankton. Limnol. Oceanogr. 21: 784-796

Nival, P., Carlotti, F., Sciandra, A. (1988). Modelling of recruitment of marine species. In: Rothschild, B. J. (ed.) Toward a theory of biological-physical interactions in the world ocean. NATO series in marine sciences. KluwerAcademic Publishers, Dordrecht, p. 321-342

Paffenhöfer, G. A. (1970). The cultivation of Calanus helgolandicus under controlled conditions. Helgoländer wiss. Meeresunters. 20: 346-359

Paffenhöfer, G. A. (1971). Grazing and ingestion rates of nauplii, copepodids and adults of the marine planktonic copepod Calanus helgolandicus. Mar. Biol. 11: 286-298

Paffenhöfer, G. A. (1984). Food ingestion by the marine planktonic copepod Paracalanus in relation to abundance and size distribution of food. Mar. Biol. 80: 323-333

Paffenhöfer, G. A., Harris, R. P. (1976). Feeding, growth and reproduction of the marine planktonic copepod Pseudocalanus elongatus Boeck. J. mar. biol. Ass. U.K. 56 $327-344$

Sciandra, A. (1982). Etude d'un écosystème marin artificiel construction d'un modèle et application à l'exploitation d'un copépode pélagique Euterpina acutifrons Dana.

This article was submitted to the editor
Thèse de 3ème cycle d'Océanographie Biologique, Université P. \& M. Curie, Paris

Sciandra, A. (1986). Study and modelling of development of Euterpina acutifrons (Copepoda, Harpacticoida). J. Plankton Res. 8: 1149-1162

Smith, S. L., Lane, P. V. Z. (1985). Laboratory studies on the marine copepod Centropages typicus, egg production and development rates. Mar. Biol. 85: 153-162

Steele, J. H. (1974). The structure of marine ecosystems. Harvard University Press, Cambridge, Massachusetts

Steele, J. H., Mullin, M. M. (1977). Zooplankton dynamics. In: Goldberg, E. D., McCave, I. N., O'Brien, J. J., Steele, J. H. (eds.) The seas, Vol. 6. John Wiley \& Sons, New York, p. $857-890$

Sulkin, S. D., Van Heukelem, W. F. (1986). Variability in the length of the megalopal stage and its consequence to dispersal and recruitment in the portunid crab Callinectes sapidus Rathbun. Bull. mar. Sci. 39: 269-278

Thébault, J. M. (1985). Etude expérimentale de la nutrition d'un copépode commun (Temora stylifera Dana). Effets de la température et de la concentration de nourriture. J. exp. mar. Biol. Ecol. 93: 223-234

Wroblewski, J. S. (1984). Formulation of growth and mortality of larvae of northern anchovy in a turbulent feeding environment. Mar. Ecol. Prog. Ser. 20: 13-22

Zurlini, G., Ferrari, 1. (1979). Growth of marine copepod population in excess food supply. Boll. Zool. 46: 225-228

Manuscript first received: March 15, 1991

Revised version accepted: June 9, 1992 